\title{
Pulse oximetry, severe retinopathy, and outcome at one year in babies of less than 28 weeks gestation
}

\author{
W Tin, D W A Milligan, P Pennefather, E Hey
}

\begin{abstract}
Aim-To determine whether differing policies with regard to the control of oxygen saturation have any impact on the number of babies who develop retinopathy of prematurity and the number surviving with or without signs of cerebral palsy at one year.

Methods-An examination of the case notes of all the 295 babies who survived infancy after delivery before 28 weeks gestation in the north of England in 19901994.

Results-Babies given enough supplemental oxygen to maintain an oxygen saturation of $88-98 \%$, as measured by pulse oximetry, for at least the first 8 weeks of life developed retinopathy of prematurity severe enough to be treated with cryotherapy four times as often as babies only given enough oxygen to maintain an oxygen saturation of $70-90 \% \quad(27.2 \% \quad v$ $6.2 \%)$. Surviving babies were also ventilated longer ( $31.4 v 13.9$ days), more likely to be in oxygen at a postmenstrual age of 36 weeks ( $46 \% v 18 \%$ ), and more likely to have a weight below the third centile at discharge $(45 \% \quad v 17 \%)$. There was no difference in the proportion who survived infancy $(53 \% v 52 \%)$ or who later developed cerebral palsy $(17 \% v 15 \%)$. The lowest incidence of retinopathy in the study was associated with a policy that made little use of arterial lines.
\end{abstract}

Conclusions-Attempts to keep oxygen saturation at a normal "physiological" level may do more harm than good in babies of less than 28 weeks gestation.

(Arch Dis Child Fetal Neonatal Ed 2001;84:F106-F110)

Keywords: prematurity; retinopathy of prematurity; cerebral palsy; oxygen saturation; pulse oximetry

Department of Paediatrics, South Cleveland Hospital, Middlesbrough TS4 3BW, UK W Tin

Royal Victoria Infirmary, Newcastle upon Tyne NE1 4LP, UK

D W A Milligan

P Pennefather

E Hey

Correspondence to:

Dr Tin

wtin@freenet.co.uk

Accepted 11 November 2000
Since the first large collaborative controlled trial showed that excess oxygen could cause permanent cicatricial retinopathy of prematurity in 1956, many papers have attempted to define what constitutes a safe level of arterial oxygenation. Indwelling arterial lines and rial oxygen tension, but no controlled trial has ever shown that any of these techniques reduce the risk of permanent retinal damage. ${ }^{1}$ An important observational study using a transcutaneous technique for monitoring tension, undertaken in 1982-1984 but only published in 1992, showed that retinopathy occurred more often in babies with tensions that sensors have been widely used to monitor arte- exceeded $80 \mathrm{~mm} \mathrm{Hg}(10.7 \mathrm{kPa}){ }^{2}$ No similar study seems to have been attempted since it became commonplace to use pulse oximetry to monitor oxygen saturation.

\section{Methods}

The outcome of every pregnancy to a mother normally resident in the north of England has been studied since July 1980, ${ }^{3}$ and a prospective study of every baby born before 28 weeks gestation was undertaken between 1990 and 1994. Every surviving baby born in 1990 and 1991 was seen for full developmental assessment ${ }^{4}$ and ophthalmic review ${ }^{5}$ when 2 years old, and every surviving baby born in 19921994 was seen and assessed by a consultant paediatrician for signs of cerebral palsy when 18 or more months old, and reviewed by a consultant ophthalmologist at intervals until it was clear that any sign of acute retinopathy was regressing. An audit in 1994 showed that screening for retinopathy had conformed to national guidelines ${ }^{6}$ in all babies of less than 28 weeks gestation after $1991 .^{7}$

All the babies had been cared for in one of five referral units for at least the first 4 weeks of life, and monitored using a Critikon, Nellcor, Omedha, or Radiometer pulse oximeter throughout the time that they were in supplemental oxygen. Most had also been intermittently monitored with a transcutaneous oxygen tension monitor in the period immediately after birth, but transcutaneous monitoring was often discontinued after a few days, especially in the most immature babies with delicate, easily damaged skin. Saturation settings (which were always documented at least once an hour) have been used throughout in the analysis that follows because the transcutaneous monitors were less consistently used, especially after 1991, and often had their alarm limits muted, or adjusted so that the saturation alarm was triggered before the tension alarm.

Policy with regard to oxygen saturation was ascertained retrospectively by questioning senior medical and nursing staff, and confirmed by reference to written ward protocols and by sampling the case notes. One unit changed its policy once during the study period, and outcome in this unit has been assessed by reference to the policy in operation at the time the baby was under care. Staff always aimed to maintain saturation in the top half of the target range (particularly when the lower limit of this range was less than $85 \%$ ). No formal attempt was made to document how often saturation fell outside the recommended management 


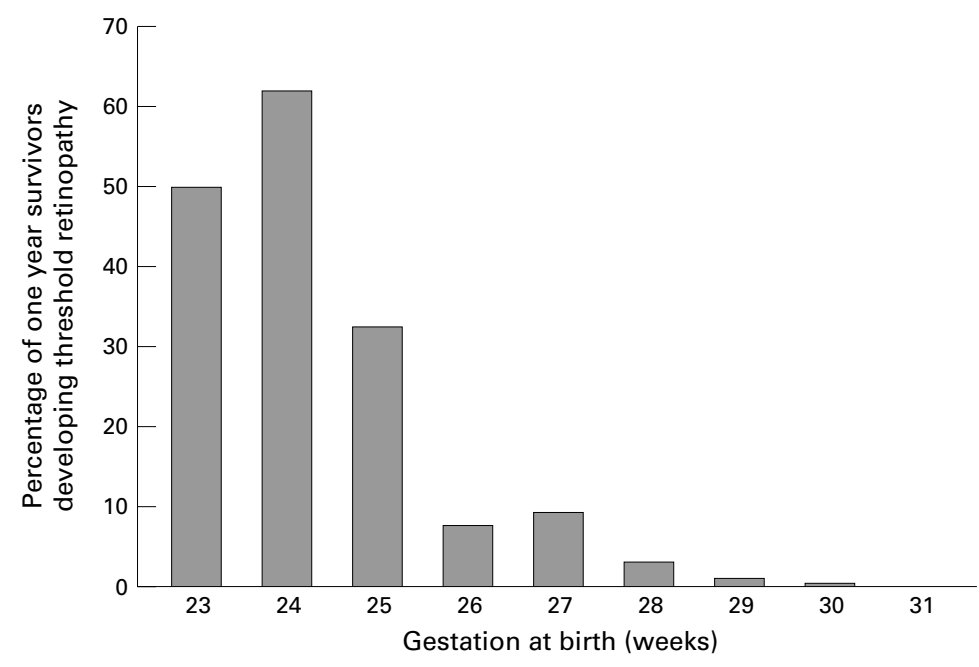

Figure 1 Incidence of threshold (grade 3+) retinopathy and its relation to gestation at birth in the 566 one year survivors from a population based study of 781 babies of 23-31 weeks gestation born in 1990-1991.

Table 1 Outcome at one year in babies of 23-27 weeks gestation at birth and its relation to target levels of fractional oxygen saturation

\begin{tabular}{llccc}
\hline $\begin{array}{l}\text { Target } \mathrm{O}_{2} \\
\text { saturation }\end{array}$ & $\begin{array}{l}\text { No of babies } \\
\text { admitted }\end{array}$ & One year survivors & $\begin{array}{l}\text { One year survivors } \\
\text { with cerebral palsy }\end{array}$ & $\begin{array}{l}\text { One year survivors } \\
\text { with threshold } \\
\text { retinopathy }\end{array}$ \\
\hline $88-98 \%^{\star}$ & 123 & $65(52.8)$ & $11(16.9)$ & $18(27.7)$ \\
$85-95 \%$ & 235 & $128(54.5)$ & $20(15.6)$ & $20(15.6)$ \\
$84-94 \%$ & 84 & $37(44.0)$ & $6(16.2)$ & $5(13.5)$ \\
$70-90 \%$ & 126 & $65(51.6)$ & $10(15.4)$ & $4(6.2)$ \\
\hline
\end{tabular}

Values in parentheses are percentages.

*Measurements made using a Nellcor pulse oximeter (functional saturation).

limits, but review of a random sample of case notes quickly showed that narrowly set limits were broached much more often than wider limits, and that staff occasionally responded in this situation by "muting" the saturation alarm altogether.

Ventilatory support was defined as the length of time the baby spent with an airway tube below the vocal cords, and gestational age calculated on the basis of the mother's menstrual history as confirmed by an ultrasound assessment of fetal size at $15-19$ weeks. ${ }^{8}$ Retinopathy was assessed by one of a small group of collaborating ophthalmologists and "threshold" retinopathy defined as stage 3 plus acute retinopathy extensive enough to merit cryotherapy using the entry criteria for the CRYOROP trial, ${ }^{9}$ or permanent (cicatricial) retinal scarring in a few of the preterm babies born in 1990-1991 in whom early serial screening was suboptimal. All retinal treatment was undertaken in one of two units.

\section{Results}

Babies of less than 28 weeks gestation were the focus of this study because review of a larger group showed that these are at greatest risk of threshold retinopathy (fig 1). All had been monitored with a pulse oximeter continuously throughout the time they were in receipt of respiratory support or receiving supplemental oxygen in hospital. Monitoring for hyperoxia did not usually begin until the baby was about 2-3 hours old, and babies with bronchopulmonary dysplasia who were at least 8 weeks old and whose retinal vasculature was mature received

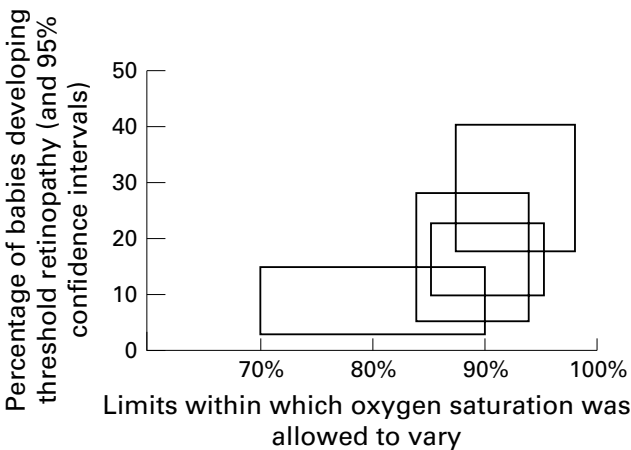

Figure 2 Relation between the target range for oxygen saturation and the proportion of survivors so nursed who later developed severe (grade 3+) retinopathy of prematurity. A comparison of four policies. Staff aimed to keep saturation in the upper half of the target range.

liberal oxygen supplementation. ${ }^{10}$ With these two exceptions, policy and practice with regard to oximeter monitoring had conformed at all times to one of four clear patterns (table 1).

Differences in policy with regard to oxygen saturation had no effect on survival or on the proportion of survivors who developed cerebral palsy, but did have a major impact on the proportion who developed threshold retinopathy. Babies nursed with a monitor set to alarm if oxygen saturation fell outside the range $70-90 \%$ had a $6.2 \%$ (95\% confidence interval (CI) 1.7 to $15.0 \%$ ) chance of developing retinopathy as severe as this; those nursed with a monitor set to maintain a saturation of $88-98 \%$ had a $27.7 \%$ (17.3 to $40.2 \%$ ) chance of developing this degree of retinopathy (fig 2). Standardisation for minor differences in the distribution of gestational age in the four study groups did not abolish the significance of these findings $(\mathrm{p}<0.01)$.

Surviving babies required ventilation and continuous supplemental oxygen for longer when the target saturation was high. Babies given enough oxygen to maintain an oxygen saturation of $88-98 \%$ were ventilated for an average of 31.4 days, and given supplemental oxygen for an average of 96 days; those maintained at saturations of $70-90 \%$ were ventilated for 13.9 days and in oxygen for 40 days (fig 3). Examination of the four management policies showed a positive correlation between target saturation and mean time to extubation.

All the 65 long term survivors nursed in enough oxygen to maintain an oximeter reading of $88-98 \%$ in the neonatal period had an arterial line inserted, and regular samples taken for an average of 12 days with a view to keeping the arterial $\mathrm{Po}_{2}$ below $12 \mathrm{kPa}$; only six of the 65 survivors managed at saturations of $70-90 \%$ ever had an arterial line inserted, or any arterial blood gas measurements taken, and only two had a line in place for more than a week. Four of the 65 long term survivors nursed in enough oxygen to maintain a saturation of $88-98 \%$ were registered as blind due to retinopathy at follow up, but none of the 65 cared for at saturations of $70-90 \%$ were so registered. The weight centiles of the babies nursed in enough oxygen to maintain a saturation of $88-98 \%$ for at least the first 8 weeks of life fell more between birth and discharge 
$(\mathrm{p}<0.01)$ than those of the babies cared for at saturations of $70-90 \%$ (fig 4 ). Twenty nine
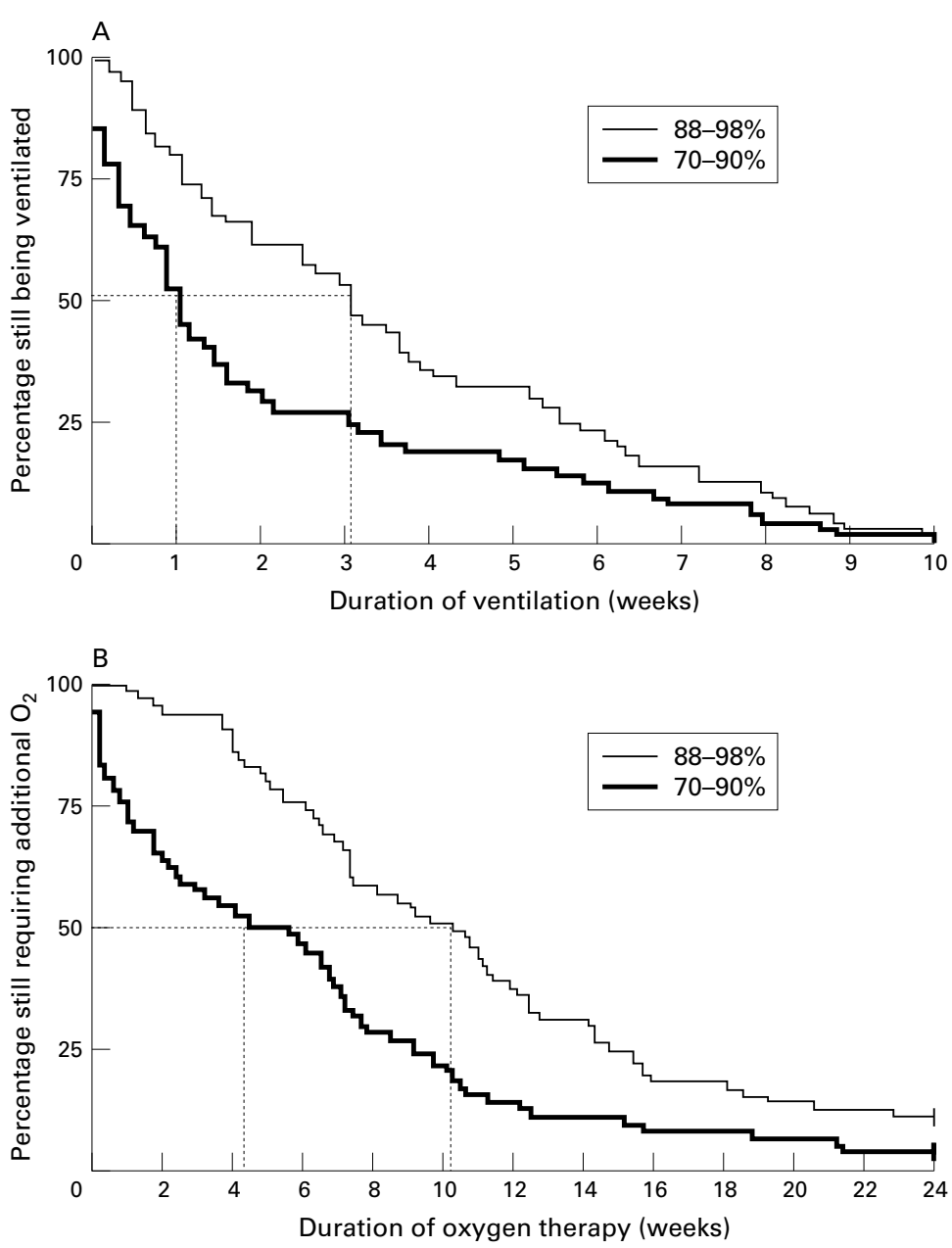

Figure 3 (A) Ventilatory support before discharge home in the one year survivors nursed in enough supplemental oxygen to maintain an oxygen saturation of 70-90\%, and to maintain a saturation of $88-98 \%$. Half the survivors in the former group were off ventilatory support by seven days; in the latter group this took 21 days. (B) Time spent in supplemental oxygen in the same two groups; $18 \%$ and $46 \%$ were still in oxygen at a postmenstrual (gestational + postnatal) age of 36 weeks; $0 \%$ and $5 \%$ were still in oxygen at one year. Log rank tests confirm that the pairs of curves differ significantly $(p<0.01)$.

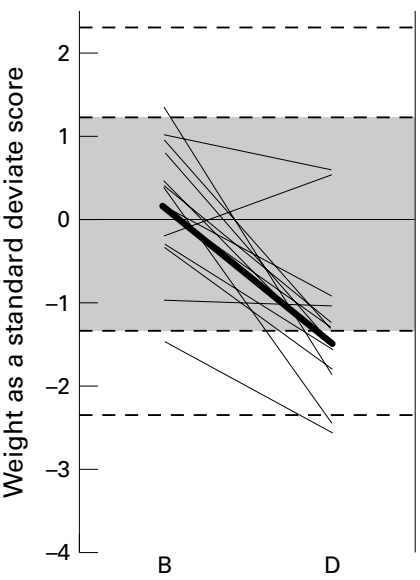

Target oxygen saturation $70-90 \%$

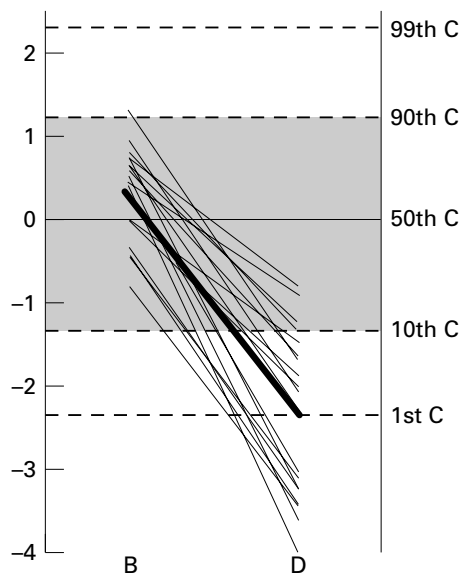

Target oxygen saturation 88-98\%
Figure 4 Change in weight centile $(C)$ between birth $(B)$ and discharge $(D)$ in the one year survivors of 23-25 weeks gestation nursed in enough oxygen to maintain an oxygen saturation of $70-90 \%$ or $88-98 \%$. The mean change in the standard deviate score for weight was -1.54 and -2.69 respectively, a difference of 1.15 (95\% CI 0.49 to 1.81 ). A smaller, also statistically significant, difference was seen in the babies of 26-27 weeks gestation $(-1.35$ and -1.98$)$.
$(45 \%)$ of the former and $11(17 \%)$ of the latter had a weight below the third centile at discharge. Table 2 outlines other differences in management and outcome.

\section{Discussion}

There is, as yet, no controlled trial evidence that any of the invasive or non-invasive techniques used to monitor oxygenation in the neonatal period have any measurable impact on clinical outcome. ${ }^{1}$ We do not even know what level of arterial oxygen tension we should be aiming for. Because mortality went undocumented in the first of the large trials of oxygen administration, we do not even know if there is a price to be paid for controlling administration strictly enough to minimise the risk of severe retinopathy.

Once equipment for monitoring transcutaneous oxygen tension became widely available, it became standard practice to aim for an oxygen tension of $6-10 \mathrm{kPa},{ }^{11}$ (limits that were slightly lower than those generally used during the years when regular arterial sampling had been the main means of minimising the risk of hyperoxia ${ }^{12}$ ) and common to set the alarm limits at 5 and $11 \mathrm{kPa}$. However, when pulse oximeters first became available, policy became more diverse. Saturation monitors are relatively poor at detecting hyperoxia, ${ }^{13-15}$ and not all commercial oximeters have similar performance characteristics. Monitors designed to record functional saturation, such as the Nellcor oximeter, consistently read about 1.5\% higher than monitors that record fractional saturation, such as the Ohmeda and Radiometer oximeters. ${ }^{16}$ Many units in the United Kingdom started setting the upper alarm limit at $95 \%$, even though this is sometimes associated with an arterial oxygen tension of more than $90 \mathrm{~mm} \mathrm{Hg}(12 \mathrm{kPa}) .{ }^{17}$ It also became common practice to set the lower limit at $85 \%,{ }^{11}$ even though a tension of $5 \mathrm{kPa}$ equates more nearly to a saturation of $80 \%,{ }^{18}$ a level still above that at which overt clinical cyanosis usually starts to become detectable. Similar divergence of practice has been documented in the United States, where surveys suggest that over a third of units currently set alarm limits that allow saturation to exceed $95 \% .^{19} 20$

Only a randomised control trial would establish whether some other unrecognised factor was responsible for the difference in the incidence of retinopathy found in this study. The present observational study does, however, strengthen the case for such a trial. The only trial designed to compare two strategies of oxygen administration from birth undertaken to date has been interpreted as suggesting that a restrictive policy may reduce pulmonary oxygen toxicity without increasing mortality. ${ }^{21-24}$ The recent STOP-ROP trial, in which babies were nursed in enough oxygen to maintain a saturation of $96-99 \%$ rather than $89-94 \%$ once prethreshold retinopathy had been detected (in the hope that this would limit the progression of retinal disease), also uncovered evidence that liberal oxygen use may cause pulmonary damage. ${ }^{25}$ 
Table 2 Early nursing management and cranial ultrasound findings in the one year survivors nursed in enough supplemental oxygen to maintain an oximeter saturation of $88-98 \%$ or $70-90 \%$ throughout the first 8 weeks of life

\begin{tabular}{lll}
\hline & $88-98 \%$ & $70-90 \%$ \\
\hline Number of one year survivors & 65 & 65 \\
Gestation (weeks) & $26.4(25.8-27.3)$ & $27.1(26.2-27.3)$ \\
Birth weight $(\mathrm{g})$ & $910(810-1018)$ & $940(855-1074)$ \\
Male sex (\%) & 55 & 46 \\
Number given $20 \mu \mathrm{g} / \mathrm{kg}$ IM vitamin E at birth & 65 & 16 \\
Number given IV amino acids \pm lipid & 62 & 12.1 \\
$\quad$ Mean time given (in those so managed) (days) & 19.2 & 2 \\
Number with an arterial line in place $\geqslant 7$ days & 49 & 13 \\
Blood transfusions given & $5(3-8)$ & $14(9-20)$ \\
Number given >2 transfusions & 55 & 2 \\
First fully enterally fed (days) & $25(18-34)$ & 6 \\
Surgery for necrotising enterocolitis & 0 & 5 \\
Cerebral ultrasound findings & 4 & 5 \\
Intraparenchymal haemorrhage & 5 & \\
Haemorrhagic ventriculomegaly & 5 & \\
Periventricular leucomalacia & &
\end{tabular}

Where applicable, values are median (interquartile range ).

IM, Intramuscular; IV, intravenous.

Oxygen delivery depends on cardiac output and on tissue perfusion as much as on arterial saturation, ${ }^{26}$ so it is arguable that, although arterial tension (or some reliable surrogate of this) is probably the best way of minimising the retinal hazard associated with hyperoxia in the very preterm baby, measurement of central venous saturation provides a better measure of the adequacy of tissue delivery. ${ }^{27}$ The babies in this study who were managed at saturations of $70-90 \%$ seldom had any arterial lines inserted or arterial blood gas measurements taken. Ventilator support was managed by taking, every six to eight hours, capillary or venous blood gas samples supplemented on occasion by transcutaneous $\mathrm{PCO}_{2}$ measurements, while Doppler ultrasound was used to monitor systolic blood pressure non-invasively. ${ }^{28}$ Because relatively little blood was taken for laboratory purposes, only 13 of the 65 long term survivors needed more than two blood transfusions before discharge (table 2 ). The result certainly calls into question the unsubstantiated belief that arterial sampling is essential if the risk of retinopathy is to be minimised. ${ }^{11}{ }^{12}$ Oximeters and indwelling sensors are actually of comparable accuracy when saturation is in the range $70-90 \% .{ }^{17}{ }^{29}$ Preterm babies requiring many blood transfusions have an increased incidence of retinopathy, and it has been suggested that this association could be causal, ${ }^{30}$ although a recent small controlled trial found no support for such a view. ${ }^{31}$ Were such a link to be established, it could even be argued that regular arterial sampling, by increasing the number of transfusions required, actually increases the risk of retinopathy.

Whatever the explanation for the variation in the amount of threshold retinopathy seen in this observational study, there can be little doubt that policy differences with regard to oxygenation had an impact on the amount of ventilatory support provided and therefore on the total cost of care before discharge (fig 3). In this respect the range of saturation deemed acceptable by the most permissive of the four policies may have been as influential as the degree of desaturation allowed because the mean saturation achieved with this policy, in the first two days after extubation, exceeded
$82 \%$ in all but eight of the 65 long term survivors. It has been suggested that fluctuation in oxygenation, rather than the absolute level experienced, does most to render the preterm retina vulnerable to severe retinopathy. ${ }^{32} 33$ While such a suggestion may seem hard to reconcile with the finding that threshold retinopathy was least often seen with the policy that allowed the widest range of saturation, it needs to be remembered that, because of the shape of the dissociation curve, a small change in saturation masks a wider change in partial pressure when saturation exceeds $90 \%$ than when saturation is lower than this.

It has been reported that babies with subclinical cyanosis grow less well, ${ }^{34-36}$ but that was not true of the babies in this observational study (fig 4). The present finding does not invalidate this general proposition, but does imply that a sustained period of ventilatory support can seriously compromise growth in the period immediately after birth, even if the baby is better oxygenated during this period and also offered parenteral nutrition.

The wide range of clinical practice shown by this study has other implications. It has recently become common practice to adjust for differences in initial disease severity when assessing the care provided by different neonatal units, or groups of units. ${ }^{37}$ The simplest and most widely used system (the Clinical Risk Index for Babies (CRIB)) uses information on the amount of oxygen given to the baby in the first 12 hours of life, but any baby cared for in a unit that aims for an oxygen saturation of $70-90 \%$ will inevitably generate a CRIB score that is lower than would have been assigned to the same baby in a unit that aims for an oxygen saturation of $88-98 \%$. As information on oxygen requirement accounts for up to $39 \%$ of the current score, failure to allow for this difference undermines the generalisability of the score. ${ }^{38}$

Current guidelines suggest that retinopathy should be looked for in all babies of less than 32 weeks gestation, ${ }^{39}$ implying that these are the babies most in need of monitoring for hyperoxia. However, no case of acute threshold retinopathy has been seen in a baby of more than 30 completed weeks gestation in the north 
of England in the last eight years, and only two cases at 30 weeks gestation (one in every 300 births at this gestation). A six year study in Birmingham also found much the same thing, ${ }^{40}$ as did studies from Tennessee in America ${ }^{41}$ and New South Wales in Australia. ${ }^{42}$ As there is no evidence that light for dates babies are any more prone to severe retinopathy than normal weight babies, there is no logic in using birth weight, as well as gestational age, when defining which babies merit monitoring for hyperoxia (or ophthalmic screening) as long as gestational age has been reliably determined.

Although healthy preterm babies maintain a saturation in excess of $95 \%$ most of the time, ${ }^{43}$ we conclude that artificial attempts to keep arterial oxygenation at a "physiological" level may do more harm than good in the first few weeks of life. The issue has been raised previously ${ }^{44}$ and certainly deserves more study, particularly in babies of less than 30 weeks gestation. Such levels are certainly higher than the retina, or the brain, would normally experience during fetal life.

We are grateful to all the members of the Northern Neonatal Network for providing data for this study, to John Clarke, Michael Clarke, David Cottrell, David Inglesby, and Nicholas Strong for ophthalmic information and advice, and to Dr Dale Phelps for reviewing an early draft of this report. Neonatal Phelps for reviewing an early draft of this report. Neonatal
information on the children born in 1990-1992 came from the information on the children born in 1990-1992 came from the
senior nurses who organised the Northern Neonatal Nursing senior nurses who organised the Northern Neonatal Nursing
Initiative, ${ }^{4}$ and information on the survivors was collated by Initiative, ${ }^{4}$ and information on the survivors was collated by
Susan Fritz from the two year developmental assessment Susan Fritz from the two year developmental assessment
undertaken by W $\mathrm{T}$ and the two year ophthalmic assessment undertaken by W T and the two year ophthalmic assessment
undertaken by P P. Information on families resident in South undertaken by P P. Information on families resident in South
Cumbria was provided by Monica Placzek and the late Donald Bell. Unni Wariyar helped collect data on the children born in 1993-1994. The 1994 retinopathy audit ${ }^{7}$ was undertaken by Nick Ziakas. The final report was drafted by $\mathrm{E} H$ with statistical advice from Angus McNay.

1 Duc G, Sinclair JC. Oxygen administration. In: Sinclair JC, Bracken $\mathrm{MB}$, eds. Effective care of the newborn infant. Oxford: Oxford University Press, 1992:178-99.

2 Flynn JT, Bancalari E, Snyder ES, et al. A cohort study of transcutaneous oxygen tension and the incidence and severity of retinopathy of prematurity. $N$ Engl $\mathcal{f} \mathrm{Med}$ 1992;326:1050-4

3 Tin W, Wariyar U, Hey E. Changing prognosis for babies of less than 28 weeks' gestation in the north of England less than 28 weeks gestation in the north of
between 1983 and 1994. BMF 1997;314:107-11.

4 Northern Neonatal Nursing Initiative Trial Group. Randomised trial of prophylactic early fresh-frozen plasma or gelatin or glucose in preterm babies: outcome at two years. gelatin or glucose in prete
Lancet 1996;348:229-32.

5 Pennefather PM, Clarke MP, Strong NP, et al. Ocular outcome in children born before 32 weeks' gestation. Eye
ond al a outcome in children bor

6 Fielder AR, Levene MI. Screening for retinopathy of prematurity. Arch Dis Child 1992;67:860-7.

7 Ziakis N, Clarke MP, Cottrell DG, et al. Compliance with the guidelines of screening for retinopathy of prematurity in the northern region of England. In: Reibaldi A, D Pietro M, Scuderi A, et al, eds. Progress in retinopathy of prematurity. Amsterdam: Kugler, 1997:37.

8 Wariyar U, Tin W, Hey E. Gestational assessment assessed. Arch Dis Child Fetal Neonatal Ed 1997;77:F216-20.

9 Cryotherapy for Retinopathy of Prematurity Cooperative Group. Multicentre trial of cryotherapy for retinopathy of prematurity. Snellen visual acuity and structural outcome at $5 \frac{1 / 2}{2}$ years after randomisation. Arch Ophthalmol at $51 / 2$ years after

10 Halliday HL, Dumpit FM, Brady JP. Effects of inspired oxygen on echo-cardiographic assessment of pulmonary gen on echo-cardiographic assessment of pulmonary vascular resistance and myocardial contractility in
chopulmonary dysplasia. Pediatrics 1980;65:536-40

11 Report of a Joint Working Group of the British Association of Perinatal Medicine and the Research Unit of the Royal College of Physicians. Development of audit measures and guidelines for good practice in the management of neonatal respiratory distress syndrome. Arch Dis Child 1992;67:1221-7.

12 American Academy of Pediatrics and American College of Obstetricians and Gynaecologists. Guidelines for perinatal care. 4th ed. Elk Grove Village: IL, 1997:189-91.

13 Wasunna A, Whitelaw AGL. Pulse oximetry in preterm infants. Arch Dis Child 1987;2:957-61.

14 Bucher HU, Fanconi S, Baeckert P, et al. Detection of hyperoxemia in newborn infants by pulse oximetry. Pediatrics 1989;84:226-30.
15 Poets CF, Southall DP. Non-invasive monitoring of oxygenation in infants and children: practical consider tions and areas of concern. Pediatrics 1994:93:737-46.

16 Thilo EH, Anderson D, Wassstein ML, et al. Saturation by pulse oximetry: comparison of the results obtained by instruments of different brands. F Pediatr 1993;122:620-6.

17 Brockway J, Hay WW. Prediction of arterial partial pressure of oxygen with pulse oxygen saturation measurements. $\mathcal{f}$ Pediatr 1998;133:63-6.

18 Hay WW, Thilo E, Curlander JB. Pulse oximetry in neonatal medicine. Clin Perinatol 1991;18:441-72.

19 Phelps DL, Colf NE. Home oxygen administration and retinopathy of prematurity: survey of 1988 practices. $A m \mathcal{F}$ Dis Child 1990;144:141-2.

20 Vijayakumar E, Ward GJ, Bullock CE, et al. Pulse oximetry in infants < $1500 \mathrm{gm}$ at birth on supplemental oxygen: a national survey. FPerinatol 1997;17:341-5.

21 Usher R. Controlled series evaluation of oxygen therapy in respiratory distress syndrome. I. Radiological evidence of pulmonary oxygen toxicity [abstract]. Pediatr Res 1970;2:429-30

22 Usher R. Liberal versus restricted indications for oxygen in
RDS: a controlled trial [abstract]. Pediatr Res 1970;4:469. Usher R. Treatment trial [abstract]. Pediatr Res 1970;4:469. Winters RW, ed. Body fluids in pediatrics. Boston: Little Brown, 1973:303-37.

24 Coats AL, Desmond K, Willis D, et al. Oxygen therapy and longterm pulmonary outcome of respiratory distress in newborns. Am F Dis Child 1982;136:892-5.

25 The STOP-ROP Multicenter Study Group. Supplemental therapeutic oxygen for prethreshold retinopathy of prematurity (STOP-ROP), a randomised, controlled trial. I. Primary outcomes. Pediatrics 2000;105:295-310.

26 Schutze A, Whyte RK, Way RC, et al. Effect of the arterial oxygenation on cardiac output, oxygen extraction and oxygenation on cardiac output, oxygen extraction and mechanical ventilation. Pediatrics 1995;126:777-84.

27 van der Hoeven MAHBM, Maetzdorf WJ, Blanco CE. Continuous central venous oxygen saturation $\left(\mathrm{ScvO}_{2}\right)$ measurement using a fibre optic catheter in newborn infants. Arch Dis Child Fetal Neonatal Ed 1996;74:F177-81.

28 Northern Neonatal Nursing Initiative. Systolic blood pressure in babies of less than 32 weeks gestation in the first year of life. Arch Dis Child Fetal Neonatal Ed 1999;80:F38-42.

29 Morgan C, Newell SJ, Ducker DA, et al. Continuous neonatal blood gas monitoring using a multiparameter intraarterial sensor. Arch Dis Child Fetal Neonatal Ed 1999;80:F93-8.

30 Cooke RWI, Clark D, Hickey-Dwyer M, et al. The apparent role of blood transfusions in the development of retinopathy of prematurity. Eur F Pediatr 1993;152:833-6.

31 Brooks SE, Marcus DM, Gilles D, et al. The effect of blood transfusion protocol on retinopathy of prematurity: a prospective randomised trial. Pediatrics 1999;104:514-18.

32 Saito Y, Omoto T, Cho Y, et al. The progression of retinopathy of prematurity and fluctuation in blood gas tension. Graefes Arch Clin Exp Ophthalmol 1993;231:151-

33 Cunningham S, Flack BW, Elton RA, et al. Transcutaneous oxygen levels in retinopathy of prematurity. Lancet 1995;346:1464-5.

34 Groothuis JR, Rosenberg AA. Home oxygen promotes weight gain in infants with bronchopulmonary dysplasia. Am f Dis Child 1987;141:992-5.

35 Hudak BB, Allen MC, Hudak ML, et al. Home oxygen therapy for chronic lung disease in extremely low birthweight infants. Am f Dis Child 1989;143:357-60.

36 Moyer-Mileur LJ, Nielson DW, Pfeffer KD, et al. Eliminating sleep-associated hypoxaemia improves growth in infants with bronchopulmonary dysplasia. Pediatrics 1996;98:779-83.

37 Wilkinson AR. Scoring systems for neonatal illness. In: Hansen TN, McIntosh N, eds. Current topics in neonatology. London: WB Saunders, 1997;2:1-20.

38 Tarnow Mordi WO, Parry G, Moore J, et al. The CRIB (Clinical Risk Index for Babies) score: a tool for assessing initial neonatal risk and comparing performance of neonatal intensive care units. Lancet 1993;342:193-8.

39 Royal College of Ophthalmologists and British Association of Perinatal Medicine. Retinopathy of prematurity. Guidelines for screening and treatment. Report of a joint working party. London: Royal College of Ophthalmologists, 1995.

40 Goble RR, Jones HS, Fielder AR. Are we screening too many babies for retinopathy of prematurity? Eye 1997;11:507-14.

41 Wright K, Anderson ME, Walker E, et al. Should fewer prematures be screened for retinopathy of prematurity in the managed care era. Pediatrics 1998;102:31-4.

42 Todd DA, Cassell C, Kennedy J, et al. Retinopathy of prematurity in infants $<32$ weeks gestation at birth in New South Wales in 1993 and 1994. F Paediatr Child Health 1999;35:355-7.

$43 \mathrm{Ng} \mathrm{A}$, Primhak RA, Shaw NJ. Arterial oxygen saturation profiles in healthy preterm infants. Arch Dis Child Fetal Neonatal Ed 1998;79:F64-6.

44 Rooth G, Engleson G, Törnblom M. A follow up study of premature infants treated with low oxygen tension. Acta Paediatr Scand 1966;55:85-7. 